\title{
Oxide Film Properties on an Interstitial-Free Manganese alloyed Steel in Sodium Sulphate Solution
}

\author{
Hongxing Chen ${ }^{1,3}$, Jianzhong $\mathrm{Li}^{2, *}$, Pin $\mathrm{Du}^{2}$, Zihan $\mathrm{Yu}^{2}$, Changsheng Liu ${ }^{1}$ \\ ${ }^{1}$ School of Materials Science and Engineering, Northeastern University, Shenyang 110819, China; \\ ${ }^{2}$ School of Metallurgy, Northeastern University, Shenyang 110819, China; \\ ${ }^{3}$ Baoshan Iron \& Steel CO., LTD., Shanghai 201900,China \\ *E-mail: lijz@mail.neu.edu.cn
}

doi: $10.20964 / 2018.05 .81$

Received: 6 February 2018 / Accepted: 13 March 2018 / Published: 10 April 2018

\begin{abstract}
Components of oxide films on interstitial-free (IF) manganese alloyed steel significantly affect corrosion resistance, and the formation of oxide films and their properties are closely related to the enrichment of alloying elements and the structure of IF manganese alloyed steel. The components and electrochemical properties of oxide films formed on IF manganese alloyed steel were measured by $\mathrm{X}$ ray photoelectron spectroscopy (XPS) and electrochemical tests using $1 \times 10^{-5} \mathrm{~mol} / \mathrm{L} \mathrm{Na}_{2} \mathrm{SO}_{4}$ solution as an electrolyte for different annealed samples with Mn content (wt\%) from 0.079 to 0.556 . The results showed that the corrosion resistance of oxide films generated on IF manganese alloyed steel decreases with Mn enrichment. According to analysis by X-ray diffraction (XRD) and electron backscatter diffraction (EBSD), with augmented Mn content, the crystal-oriented distribution of samples becomes obviously concentrated, and the volume fraction of $\{111\} / / \mathrm{ND}$ texture increases. It is confirmed the significant role of the Mn content on grain refinement of IF manganese alloyed steel. In addition, the oxides of other elements ( $\mathrm{Si}$ and $\mathrm{Fe}$ ) tend to hold steady with increasing Mn content.
\end{abstract}

Keywords: IF manganese alloyed steel, oxide film, corrosion resistance, texture, grain orientation

\section{FULL TEXT}

(C) 2018 The Authors. Published by ESG (www.electrochemsci.org). This article is an open access article distributed under the terms and conditions of the Creative Commons Attribution license (http://creativecommons.org/licenses/by/4.0/). 